\author{
So Where Do You See This Going? The Effects of Commitment Asymmetry and \\ Asynchrony on Relationship Satisfaction and Breakup \\ Kiersten Dobson ${ }^{1}$, Brian G. Ogolsky ${ }^{1}$, \& Sarah C. E. Stanton ${ }^{2}$ \\ ${ }^{1}$ University of Illinois at Urbana-Champaign \\ 2University of Edinburgh
}

\begin{abstract}
Author Note
This research was supported by HATCH Grant 793-349 awarded to Brian G. Ogolsky from the U.S. Department of Agriculture/National Institute of Food and Agriculture, and New Investigator Grant ES/S005749/1 awarded to Sarah C. E. Stanton from the UK Economic and Social Research Council (ESRC).

Direct correspondence to Kiersten Dobson, University of Illinois at UrbanaChampaign, Department of Human Development and Family Studies, 222 Bevier Hall, 905 S. Goodwin Ave, Urbana, Illinois, 61801, USA. Email: kdobson@illinois.edu
\end{abstract}

This document is a preprint and may not reflect the final version of the published manuscript. 


\begin{abstract}
We test the contribution of multiple types of romantic partners' commitment asymmetry (discrepancies between partners' commitment at a single time point) and asynchrony (discrepancies in the progression of commitment over time) to later relationship satisfaction and breakup. In three dyadic studies $(N=6,960$ couples) over months (Study 1), days (Study 2), and years (Study 3), commitment asymmetry and asynchrony consistently did not predict satisfaction or breakup when controlling for commitment scores of individuals and their partners. Only one's own commitment and proportion of downturns in commitment (when participants reported lower commitment than the previous time point) consistently predicted satisfaction across all three studies. For breakup, women's (but not men's) commitment was consistently negatively associated with breakup and proportion of downturns was consistently positively associated with breakup. Our findings indicate that, contrary to some significant findings in prior research, commitment asymmetry and asynchrony are not indicative of future relationship outcomes.
\end{abstract}

Keywords: Commitment asynchrony, commitment asymmetry, satisfaction, breakup, intimate relationships, longitudinal 


\section{So Where Do You See This Going? The Effects of Commitment Asymmetry and Asynchrony on Relationship Satisfaction and Breakup}

Romantic relationships play an important role in physical and mental health (HoltLunstad et al., 2008), and both positive and negative relationship experiences can influence personal and partner well-being (e.g., Antonucci et al., 2001; Stanton et al., 2020). An integral and common marker of the state of a romantic relationship is each partner's commitment. According to the investment model (Rusbult, 1980,1983), commitment stems from relationship satisfaction, quality of alternatives, and investments in the relationship. Commitment, in turn, influences partners' stay-leave decisions and how satisfying and stable the relationship is over time (e.g., Machia \& Ogolsky, 2021). However, it is common for one partner to be more committed than the other at any given point in a relationship. This commitment asymmetry is associated with lower relationship stability, adjustment, and satisfaction, and higher conflict and aggression (Sprecher et al., 2006; Stanley et al., 2017). Notably, in previous research asymmetry has been measured in a variety of ways, each with empirical and practical limitations. Additionally, measurement and replication issues have recently been highlighted in relationship science and psychology more broadly (e.g., Schimmack, 2020). In the current research, we aim to resolve prior measurement issues by (1) comparing different ways of measuring commitment asymmetry and (2) introducing a new method examining commitment asynchrony (i.e., discrepancies between partners in their progression of commitment over time). We also test whether commitment asymmetry and asynchrony predict relationship satisfaction and breakup over days, months, and years. 
Asymmetry in romantic partners' relationship evaluations has been operationalized in several different ways. Some research has categorized romantic partners into symmetrical or asymmetrical groups based on their own and their partner's responses to the same sets of questions (e.g., Stanley et al., 2017; Weiser et al., 2018). For example, Stanley et al. (2017) examined asymmetrical commitment by coding relationships in which partners' commitment scores differed by 1 standard deviation $(S D)$ or more as asymmetrical. This categorical asymmetry was then used as a predictor of relationship outcomes, revealing that asymmetrical (vs. symmetrical) commitment was associated with lower relationship adjustment, more conflict, and more aggression. However, there are several problems associated with categorizing continuous variables (e.g., van Walraven \& Hart, 2008), including a loss of statistical power, residual confounding, and biased results due to often data-derived or arbitrary cut-off points. Using this approach, it is also unclear what asymmetry means for couples on a practical level. For example, a couple who differs by $0.90 S D$ will be categorized differently than one who differs by $1.1 S D$, but it is unlikely that these couples have markedly different lived experiences. Thus, categorizing may not be the best methodological or practical approach to examining asymmetry in romantic relationships.

Other researchers have relied on relationship partners themselves to identify whether the relationship is asymmetrical using a perceived asymmetry approach. That is, researchers have asked participants to indicate who, between themselves and their partner, is the more involved partner. For example, Sprecher et al. (2006) asked participants to rate "Who would you say is more emotionally involved in the relationship?" on a 7-point scale with equal involvement as the midpoint, and the opposite ends of the 
scale representing greater involvement by one partner versus the other. Equal involvement in this study (i.e., selecting the midpoint) was associated with greater relationship satisfaction and stability. Perceptions of asymmetry have also been measured via participants reporting their perceptions of their own and their partner's level of the variable of interest (e.g., Tan et al., 2020). However, measuring asymmetry in this way does not assess true asymmetry between partners, and it assumes participants' perceptions accurately reflect their partners' experiences. Thus, the perceived asymmetry approach is interesting and potentially important, but testing it falls outside the scope of the current research.

A final approach to measuring asymmetry involves calculating the absolute value of the difference between partners' scores on the same scale (e.g., Mark \& Murray, 2012). This continuous asymmetry approach accounts for the difference between the partners but fails to account for each partner's individual score on the variable. Thus, couples who are highly committed but differ slightly would be assigned the same value as those who have low commitment but differ by the same amount. These couples are likely to have very different lived experiences, and therefore this method may not effectively capture distinct types of asymmetric relationships. To adjust for this, some researchers have included the absolute difference score and each partner's score in their models (e.g., Hadden et al., 2014), arguing that controlling for individual main effects provides greater confidence that it is the discrepancy between partners that is driving the effect, rather than each partner's score for that variable (Hadden et al., 2014). This addition allows for a more accurate representation of the impact of asymmetry specifically; however, a major limitation of this approach (and the other approaches described above) is that it does not consider how commitment 
develops or changes over time. That is, these methods generally rely on examining asymmetry at a single time point, rather than examining how relationships may progress at different rates for each partner.

Romantic partners' commitment fluctuates over time, and these fluctuations are associated with relationship quality and dissolution (e.g., Knopp et al., 2014; Ogolsky et al., 2016). Fluctuations in commitment may not always occur simultaneously between partners, giving rise to the potential for asymmetry to also fluctuate over time. Our research involves partners' multiple reports of their commitment over time, allowing us to examine the effects of commitment asymmetry at specific time points, but also how differences in the progression of the relationship can differ between partners (asynchrony). To our knowledge, only one study has examined differences in couples' progression of commitment over time: Finn et al. (2020) found that couples who later broke up had a stronger within-couple correlation in their changes in commitment over time than those who stayed together, likely due to partners' rapidly decreasing levels of commitment as they approached breakup. These findings were inconsistent with both previous research on asymmetry in commitment and with the authors' own hypotheses, and thus would benefit from replication. In the current research, we examine whether differences in partners' change in commitment over time (i.e., asynchrony in slopes) is associated with later satisfaction and breakup.

Finally, we assess an additional method of examining differences in partners' progression of commitment over time; namely, differences in the proportion of downturns in commitment. Instability in commitment in general is bad for relationships (Knopp et al., 2014), but downturns, or decreases in commitment from previous levels, may be 
particularly detrimental given the profound impact of negative experiences (for reviews, see Baumeister et al., 2001; Rozin \& Royzman, 2001). Downturns in commitment predict lower passion and a higher likelihood of breakup (Niehuis et al., 2016; Ogolsky et al., 2016). Thus, we examine differences between partners in the frequency of downturns in commitment over time (i.e., asynchrony in downturns), determining how this may contribute to relationship quality and dissolution.

In the current research, we seek to resolve some important measurement issues in relationship science by attempting to replicate and extend past research examining the links between romantic partners' commitment asymmetry and asynchrony and their relationship satisfaction and likelihood of breakup. We include multiple operationalizations of asymmetry and asynchrony to compare results across each methodological approach. Specifically, we 1) categorize relationships as symmetrical or asymmetrical (categorical asymmetry; Model 1a); 2) calculate the absolute value of the difference between partners' scores (continuous asymmetry; Model 2a); 3) add the main effects of each partner's commitment to the previous models allowing for greater confidence that it is the discrepancy between the partners that is driving the effect (Models $1 \mathrm{~b}$ and 2b); 4) examine differences in partners' proportion of downturns in commitment over time (asynchrony in downturns; Model 3a) and account for each partners' number of downturns (Model 3b); and 5) examine differences in partners' progression of commitment over time by calculating differences in their slopes (asynchrony in slopes; Model 4a), account for each partner's slopes (Model 4b), and account for the difference between partners' intercepts and each partner's intercept (Model 4c). 
We predicted that, in general, partners' levels of asymmetry and asynchrony would be negatively associated with their future relationship satisfaction and positively associated with breakup. Additionally, to determine whether asymmetry and asynchrony are pervasive issues in romantic relationships, we describe the typical level of asymmetry and asynchrony in partners' commitment using each method described above. The hypotheses, methods, and analytic plan of all three studies were preregistered, and the materials, data ${ }^{1}$, output, and code are publicly available (Study 1: https://osf.io/9ts3u/; Study 2: https://osf.io/7wp4c/; Study 3: https://osf.io/sbjwk/). We report all manipulations, measures, and exclusions in these studies.

\section{Study 1}

\section{Methods}

\section{Participants}

Participants were recruited via random digit dialing of approximately 36,000 households in an urban area of the southwestern US. To be eligible, participants were required to be in a heterosexual dating relationship, never married, between 19 and 35 years old, and available over a 9-month continuous period. Initial calls identified 861 eligible individuals, 232 of whom consented to participate and whose partner also consented. Thus, 464 individuals (232 couples) completed the first interview. On average, participants were in their mid-twenties $\left(M_{\text {men }}=24.80, S D_{\text {men }}=3.86 ; M_{\text {women }}=23.26\right.$, $\left.S D_{\text {women }}=3.58\right)$ and had been in their relationship for about two years $(M=26.30$ months,

\footnotetext{
${ }^{1}$ Study 3 data belong to the German Family Panel Study and are available upon request through their website (https://www.pairfam.de/en/).
} 
$S D=21.77$ ). Our sample was ethnically representative of the local population, with $70 \%$

White, 16\% Hispanic, 8\% African American/Black, and 6\% Asian.

\section{Procedure}

Study 1 was part of a larger three-phase study conducted in the United States from 1993-1995 mapping changes in romantic partners' commitment to wed over a 9-month period. ${ }^{2}$ Phase 1 consisted of a 1-3-hour baseline interview. Phase 2 began approximately one month after Phase 1, and involved shorter, 15-30-minute monthly interviews for seven consecutive months. During months one and seven participants also completed two 10-day daily diaries, indicating their engagement in a variety of behaviors (e.g., leisure activities, chores). Finally, Phase 3 occurred approximately one month after Phase 2 and involved a 1-3-hour final interview.

\section{Measures}

Commitment to Wed. During the Phase 1 interview, participants constructed a graph of changes in their perceived chance of marriage over the course of their current relationship. Partners' commitment to wed captures unique components of commitment that may be particularly relevant for those in dating relationships; specifically, a long-term orientation and stability in expectations of long-term relationship quality (Ogolsky et al., 2016). Interviewers showed participants a blank graph that had the chance of marriage, which ranged from $0 \%$ (certain they would never marry their partner or had never thought about marriage) to $100 \%$ (certain they would eventually marry their partner), on the $y$-axis and time in months on the x-axis (Surra \& Gray, 2000). Interviewers marked important

\footnotetext{
${ }^{2}$ Data from this study were previously used in <blinded for review>'s examination of common patterns of commitment to wed.
} 
dates (e.g., date of relationship onset) on the bottom of the graph and then asked about and marked the chance of marriage today and at the beginning of the relationship. Participants indicated when they had first become aware of a change in the chance of marriage from the initial value. Interviewers plotted that value on the graph and asked participants to explain the shape of the line that should connect the two points. They then repeated this procedure for each reported change in the chance of marriage until the graph reached "today." If participants stated that they were philosophically opposed to marriage and would never marry, they were given the opportunity to graph lifelong commitment to each other rather than chance of marriage. The participants who chose this option $(N=7)$ were excluded from analyses. An additional 17 participants were excluded from analyses because their graphs showed no change in the chance of marriage $(N=13)$, had missing transcripts because of equipment failure $(N=3)$, or were extreme outliers (reported a $100 \%$ change in the chance of marriage in one day; $N=1$ ).

At each of the seven monthly interviews in Phase 2, respondents indicated whether they were dating the same partner and completed a graph of the chance of marriage from the date of the prior interview until the date of the current interview.

The Phase 3 interview took place approximately 9 months after the first interview and consisted of the same procedure. Participants first did a monthly update of the graph. They then constructed a retrospective graph of the chance of marriage from the beginning of the relationship until the day of the Phase 3 interview and completed a series of relational measures (e.g., satisfaction). Graphing portions of all interviews were audiotaped. 
Global Commitment. Global commitment was measured in Phases 1, 2.4 (the fourth Phase 2 monthly interview), and 3 with three items from Rusbult's (1980) measure of commitment and satisfaction (e.g., "For how much longer do you want your relationship to last?"), rated on a 9-point scale. Items were scored and mean aggregated such that higher scores represented higher commitment (Phase 1: $\alpha=.85$; Phase 2.4: $\alpha=.87$; Phase $3: \alpha=.90)$.

Relationship Satisfaction. Relationship satisfaction was measured in Phases 1, 2.4, and 3 using Huston and Vangelisti's (1991) Marital Opinion Questionnaire. Participants rated their relationship over the past month on ten 7-point bipolar scales (e.g., "miserableenjoyable"), as well as a single-item global measure of satisfaction ("All things considered, how satisfied or dissatisfied have you been with your relationship over the last month or so?") rated on a 7-point scale (1 = completely satisfied, 7 = completely dissatisfied). Items were scored and mean aggregated such that higher scores represented higher satisfaction (Phase 1: $\alpha=.90 ;$ Phase 2.4: $\alpha=.92 ;$ Phase 3: $\alpha=.93$ ).

Breakup. Throughout Phases 2 and 3, participants reported if they were in a romantic relationship, and if so, if it was with the same partner they started the study with. Breakup was coded ( $1=$ broke up, $0=$ still together $)$ if participants or their partners ever indicated they were no longer in a relationship or were in a relationship with a new partner.

\section{Results}

\section{Frequency of Asymmetry}

Commitment asymmetry and asynchrony were common in this sample (see Table 1), with $32.8 \%$ of couples categorized as asymmetrical at Phase 1. 
Table 1. Descriptive information regarding asymmetry and asynchrony in romantic relationships.

\begin{tabular}{lccc}
\hline Asymmetry/Asynchrony type & Study 1 & Study 2 & Study 3 \\
\hline Categorical Asymmetry & & & \\
$N$ asymmetrical (Proportion of total sample & $76(32.8 \%)$ & $64(36.0 \%)$ & $5778(18.4 \%)$ \\
$\begin{array}{l}\text { Asymmetrical) } \\
\text { Difference between partners' global commitment scores }\end{array}$ & $1.37(1.36)$ & $.89(.68)$ & $.34(.60)$ \\
$M(S D)$ & $.17(.19)$ & $.11(.10)$ & $.09(.15)$ \\
$\begin{array}{l}\text { Difference in proportion of downturns } \\
M(S D)\end{array}$ & $2.10(2.22)$ & $.03(.04)$ & $.004(.01)$ \\
$\begin{array}{l}\text { Difference in slopes } \\
M(S D)\end{array}$ & $14.07(14.74)$ & $.47(.55)$ & $.16(.22)$ \\
$\begin{array}{l}\text { Difference in intercepts } \\
M(S D)\end{array}$
\end{tabular}

Note. Global commitment scores could range from 0-8 in Study 1, 1-9 in Study 2, and 1-5 in Study 3. Commitment scores used to calculate slopes and intercepts could range from 0-100 in Study 1, 1-7 in Study 2, and 1-5 in Study 3.

\section{Association of Asymmetry and Asynchrony with Satisfaction}

To test whether asymmetry at Phase 1 predicted relationship satisfaction nine months later (Phase 3), we used multilevel modeling guided by the Actor-Partner Interdependence Model (APIM; Kenny et al., 2006), where individuals were nested within couples. We used a model building approach, where the effects of differences between partners (categorical or continuous) were first included in their respective models, followed by additional models controlling for actors' and partners' global commitment scores. In all models we predicted Phase 3 satisfaction controlling for satisfaction at Phase 1. We also differentiated between effects for males ${ }^{3}$ and females to be comparable with the asynchrony analyses (detailed below). As shown in Table 2, neither categorical nor continuous asymmetry at Phase 1 predicted differences in romantic partners' satisfaction at Phase 3, either in the base models (Models 1a and 2a) or in subsequent models

\footnotetext{
${ }^{3}$ We use sex (male/female) or gender (man/woman) to differentiate partners based on how participants identified themselves in the demographic questionnaire of each study (sex in Studies 1 and 3, gender in Study 2). When comparing across studies (e.g., in the discussion), we treat men as synonymous with males, and women as synonymous with females.
} 
controlling for actors' and partners' global commitment scores (Models $1 \mathrm{~b}$ and $2 \mathrm{~b}$ ). Actors' commitment was associated with higher relationship satisfaction nine months later for males in the categorical asymmetry model.

To test whether asynchrony was associated with later relationship satisfaction, we were unable to use global commitment scores for asynchrony as it was not measured enough times to generate slopes and intercepts using growth curve analyses. Instead, we used participants' commitment to wed from the graphing procedure in Phase 2. First, we tallied the total number of "turning points," or instances where commitment to wed changed across all seven months in Phase 2, as well as how frequently these changes were decreases in commitment to wed. We then divided the number of times participants reported a decrease in commitment to wed by the total number of instances in which they reported a change in commitment to wed to create the proportion of downturns. We calculated the difference between relationship partners' proportion of downturns, entering it as a predictor of Phase 3 satisfaction in an APIM (Kenny et al., 2006). We then ran an additional model controlling for actors' and partners' proportion of downturns. Results of the base model (Model 3a) indicated that differences between partners in their proportion of downturns over a seven-month period predicted males' and females' relationship satisfaction; however, these effects were nonsignificant when controlling for actors' and partners' proportion of downturns (Model 3b). Instead, only actors' proportion of downturns significantly predicted males' and females' satisfaction.

Next, we calculated participants' average commitment to wed score each month in Phase 2 (seven scores per person). We then conducted an unconditional two-intercept growth model (separated by sex), with Time $(0=$ Phase 2.1$)$ entered as a Level 1 predictor 
and monthly commitment to wed as the outcome. We then extracted the transformed residual scores from the unconditional growth model. We calculated the absolute value of the difference between partners' residuals for both the intercept and slope, representing differences in partners' perceptions of the trajectory of their relationship. We then ran APIMs predicting Phase 3 satisfaction. The base model included only the difference between partners' slopes, or overall trajectories (Model 4a). We then ran an additional model where each partner's slope was added (Model 4b). Finally, we added the difference between partners' intercepts (to account for initial asymmetry at Time 0) and each partner's intercept to the model (Model 4c). Results in all three models revealed that differences between partners in their trajectories of commitment over a seven-month period did not predict males' and females' relationship satisfaction over time. The actors' slope significantly predicted later relationship satisfaction for males in Model 4b (accounting for each partner's slope), and significantly predicted satisfaction for females in Model 4c (accounting for intercepts).

In sum, although commitment asymmetry and asynchrony predicted relationship satisfaction in some of the base models, no effects remained robust when controlling for individuals' own and their partner's commitment or commitment trajectories. Thus, couple-level asymmetry and asynchrony did not explain meaningful variation in relationship satisfaction over and above individual levels of commitment. 
Table 2. Study 1 effects of asymmetry and asynchrony predicting relationship satisfaction.

\begin{tabular}{|c|c|c|c|c|c|c|c|c|c|}
\hline \multirow[t]{2}{*}{ Model } & \multirow[t]{2}{*}{ Variable } & \multicolumn{4}{|c|}{ Male } & \multicolumn{4}{|c|}{ Female } \\
\hline & & $b$ & $S E$ & $\bar{p}$ & $R^{2}$ & $b$ & $S E$ & $p$ & $R^{2}$ \\
\hline Model 1a & Categorical Asymmetry & .19 & .21 & .376 & .005 & -.03 & .19 & .894 & $<.001$ \\
\hline \multirow[t]{3}{*}{ Model 1b } & Categorical Asymmetry & -.07 & .22 & .753 & .001 & -.10 & .22 & .641 & .001 \\
\hline & Actor commitment & .15 & .07 & .033 & .027 & .11 & .07 & .121 & .015 \\
\hline & Partner commitment & .14 & .06 & .027 & .030 & -.005 & .06 & .941 & $<.001$ \\
\hline Model 2a & Difference in Global Commitment & -.10 & .07 & .164 & .011 & -.07 & .06 & .295 & .007 \\
\hline \multirow[t]{3}{*}{ Model 2b } & Difference in Global Commitment & -.001 & .08 & .992 & $<.001$ & -.08 & .08 & .297 & .007 \\
\hline & Actor commitment & .14 & .07 & .059 & .021 & .09 & .07 & .177 & .011 \\
\hline & Partner commitment & .13 & .06 & .032 & .028 & -.06 & .07 & .401 & .005 \\
\hline Model 3a & Asynchrony in downturns & -1.61 & .56 & .005 & .051 & -1.41 & .44 & .002 & .061 \\
\hline \multirow[t]{3}{*}{ Model 3b } & Asynchrony in downturns & -.62 & .55 & .263 & .008 & -.44 & .48 & .361 & .005 \\
\hline & Actor's proportion of downturns & -2.56 & .43 & $<.001$ & .188 & -2.05 & .44 & $<.001$ & .125 \\
\hline & $\begin{array}{l}\text { Partner's proportion of } \\
\text { downturns }\end{array}$ & -.30 & .47 & .521 & .003 & .23 & .39 & .559 & .002 \\
\hline Model 4a & Asynchrony in slopes & -.04 & .04 & .367 & .005 & -.02 & .04 & .540 & .002 \\
\hline \multirow[t]{3}{*}{ Model 4b } & Asynchrony in slopes & -.06 & .04 & .184 & .011 & -.02 & .04 & .656 & .001 \\
\hline & Actor's slope & .09 & .04 & .008 & .045 & .06 & .03 & .054 & .024 \\
\hline & Partner's slope & -.02 & .03 & .608 & .002 & .02 & .03 & .576 & .002 \\
\hline \multirow[t]{6}{*}{ Model 4c } & Asynchrony in slopes & -.03 & .05 & .491 & .003 & .01 & .04 & .815 & $<.001$ \\
\hline & Actor's slope & .07 & .04 & .067 & .022 & .10 & .04 & .008 & .044 \\
\hline & Partner's slope & .02 & .04 & .533 & .003 & -.01 & .04 & .829 & $<.001$ \\
\hline & Difference in intercepts & -.002 & .01 & .829 & $<.001$ & -.01 & .01 & .268 & .008 \\
\hline & Actor's intercept & -.002 & .01 & .749 & .001 & .01 & .01 & .059 & .023 \\
\hline & Partner's intercept & .01 & .01 & .060 & .023 & -.01 & .01 & .272 & .008 \\
\hline
\end{tabular}

Note. Each model included an intercept for males and females, and actor's Phase 1 satisfaction (grand mean centered). Estimates of these additional effects can be found in our online supplemental material at https://osf.io/2d7je/. Effects of interest (differences between partners) are bolded. Approximate effect sizes were computed using the formula $R^{2}=\frac{\left(d f_{\text {Numerator }} / d f_{\text {Denominator }}\right) * F}{1+\left(\left(d f_{\text {Numerator }} / d f_{\text {Denominator }}\right) * F\right)}$ (Edwards et al., 2008). 


\section{Association of Asymmetry and Asynchrony with Breakup}

To test whether asymmetry and asynchrony were associated with relationship breakup over the next nine months, we used logistic regression. Base models with only the difference variables (categorical or continuous asymmetry, difference in proportion of downturns, difference in slopes) were simple logistic regressions as both the predictor and outcome were at the couple level. However, when individual level predictors (e.g., each partner's commitment) were added these became two-level models, with individuals nested within couples. We followed the specifications of Loeys et al. (2014) for conducting APIMs with categorical dyadic data using generalized estimating equations (GEEs), which are an extension of the logistic regression model that accounts for nonindependence.

As seen in Table 3, every type of asymmetry and asynchrony significantly predicted breakup in the respective base models (Models 1a, 2a, 3a, and 4a). However, when individual scores were accounted for, no asymmetry or asynchrony effects remained significant (Models 1b, 2b, 3b, 4b, 4c). Instead, females' (but not males') baseline commitment and slope were negatively associated with breakup. Females' proportion of downturns was positively associated with breakup.

In sum, although commitment asymmetry and asynchrony predicted breakup in the base models, none of these effects significantly predicted breakup when controlling for individuals' own and their partner's commitment or commitment trajectories. Thus, couple-level asymmetry and asynchrony did not explain meaningful variation in the likelihood of breakup over and above individual levels and trajectories of commitment. 
Table 3. Study 1 effects of asymmetry and asynchrony predicting breakup.

\begin{tabular}{|c|c|c|c|c|c|c|c|c|c|c|c|c|c|}
\hline \multirow{2}{*}{ Model } & \multirow{2}{*}{ Variable } & \multicolumn{4}{|c|}{$\underline{\text { Couple level variable }}$} & \multicolumn{4}{|c|}{ Male } & \multicolumn{4}{|c|}{ Female } \\
\hline & & $b$ & $S E$ & $p$ & OR & $b$ & $S E$ & $p$ & OR & $b$ & $S E$ & $p$ & $\mathrm{OR}$ \\
\hline Model 1a & $\begin{array}{l}\text { Categorical } \\
\text { Asymmetry }\end{array}$ & 1.14 & .32 & $<.001$ & 3.13 & & & & & & & & \\
\hline \multirow[t]{2}{*}{ Model 1b } & $\begin{array}{l}\text { Categorical } \\
\text { Asymmetry }\end{array}$ & -.11 & .41 & .787 & .90 & & & & & & & & \\
\hline & Actor commitment & & & & & -.15 & 11 & 172 & .86 & -.33 & .10 & .001 & .72 \\
\hline Model 2a & $\begin{array}{l}\text { Difference in Global } \\
\text { Commitment }\end{array}$ & .41 & .11 & $<.001$ & 1.51 & & & & & & & & \\
\hline \multirow[t]{2}{*}{ Model 2b } & $\begin{array}{l}\text { Difference in Global } \\
\text { Commitment }\end{array}$ & -.14 & .14 & .340 & .87 & & & & & & & & \\
\hline & Actor commitment & & & & & -.18 & .12 & 141 & .84 & -.35 & .10 & .001 & .70 \\
\hline Model 3a & $\begin{array}{l}\text { Asynchrony in } \\
\text { downturns }\end{array}$ & 2.73 & .86 & .001 & 15.33 & & & & & & & & \\
\hline \multirow[t]{2}{*}{ Model 3b } & $\begin{array}{l}\text { Asynchrony in } \\
\text { downturns }\end{array}$ & .60 & 1.07 & .577 & 1.82 & & & & & & & & \\
\hline & $\begin{array}{l}\text { Actor's proportion of } \\
\text { downturns }\end{array}$ & & & & & 1.25 & .87 & 148 & 3.49 & 2.20 & .91 & 016 & 9.03 \\
\hline Model 4a & Asynchrony in slopes & .24 & .07 & $<.001$ & 1.27 & & & & & & & & \\
\hline Model 4b & $\begin{array}{l}\text { Asynchrony in slopes } \\
\text { Actor's slope }\end{array}$ & .11 & .09 & .209 & 1.12 & .01 & .07 & .912 & 1.01 & -.18 & .08 & .028 & .84 \\
\hline \multirow[t]{3}{*}{ Model 4c } & $\begin{array}{l}\text { Asynchrony in slopes } \\
\text { Actor's slope }\end{array}$ & .06 & .11 & .603 & 1.06 & .05 & .08 & .524 & 1.05 & -.27 & .08 & .001 & .76 \\
\hline & $\begin{array}{l}\text { Difference in } \\
\text { intercepts }\end{array}$ & .01 & .01 & .418 & 1.01 & & & & & & & & \\
\hline & Actor's intercept & & & & & -.01 & .01 & .574 & .99 & -.03 & .01 & .021 & .97 \\
\hline
\end{tabular}

Note. Since we are predicting a couple-level outcome and all couples are different-sex, the actor effect for males is equal to the partner effect for females, and vice versa. Thus, we present only the actor effects. Effects of interest (differences between partners) are bolded. OR is odds ratio, which is an exponentiated $b$. 


\section{Study 2}

In Study 1, contrary to previous research and our initial hypotheses, we found that no type of commitment asymmetry or asynchrony predicted relationship satisfaction or breakup when controlling for individuals' own and their partner's commitment or commitment trajectories. However, given that the Study 1 data were collected over 25 years ago, we sought to replicate our findings in a new, contemporary sample of romantic couples. As in Study 1, we describe the typical levels of asymmetry and asynchrony between partners' global commitment and examine their links with relationship satisfaction. ${ }^{4}$ We again measured asymmetry and asynchrony in multiple ways to compare results across each methodological approach. In general, we anticipated that, consistent with Study 1, commitment asymmetry and asynchrony would not predict partners' future satisfaction. Instead, we expected that individuals' scores would better predict their future satisfaction.

\section{Methods}

\section{Participants}

The sample comprised 100 romantic couples (87 heterosexual, 9 lesbian, 1 gay, 3 other non-binary) recruited in the UK in 2020 via social media posts, magazine advertisements, and wedding fair flyers. This sample size was based on an a priori APIMPowerR analysis (https://robert-ackerman.shinyapps.io/APIMPowerR/) suggesting that 100 couples would provide $84 \%$ power for small-to-medium cross-sectional effects. To conduct our two-intercept growth models to extract slopes and intercepts, partners had to

\footnotetext{
${ }^{4}$ Study 2 spanned 2.5 months, and there were very few instances of relationship dissolution $(N=2$ couples). Thus, we examine only effects for satisfaction in Study 2.
} 
be distinguishable, and thus only data from different-gender couples $(N=89)$ were analyzed. Participants were 18-64 years of age $\left(M_{\text {years }}=24.43, S D_{\text {years }}=6.89\right)$ and were in relationships lasting 3 months to 35.50 years $\left(M_{\text {years }}=2.98, S D_{\text {years }}=4.57\right)$. Approximately $84.27 \%$ of participants were casually or exclusively dating their current partner, and $15.73 \%$ were common-law, engaged, in a civil partnership, or married.

\section{Procedure}

Data were taken from a larger longitudinal study of couples' relationship experiences. The study involved an initial 2-hour lab session (Phase 1), a 14-day diary period (Phase 2), and a follow-up survey two months later (Phase 3). For Phase 1, couples attended a lab session, provided informed consent, and then completed several tasks including a survey that contained relationship satisfaction and commitment measures.

During Phase 2, participants completed a 15-minute online survey each day for 14 consecutive days, which included a measure of commitment. Unique survey links were emailed to participants at 4:00PM each day, and partners were asked to complete their survey separately and privately before 11:59PM. Survey links were individual and set to expire at midnight the following day to ensure that partners could not complete multiple surveys at once. The average number of daily surveys completed was high (Range $=1-14, M$ $=12.96, S D=2.01)$.

Phase 3 occurred two months after Phase 2. Participants completed a final 45minute online survey, which included satisfaction and commitment measures. After finishing Phase 3, participants were debriefed and compensated up to GBP- $£ 50.00$ each based on how many parts of the study they completed.

\section{Measures}


Phase 1 and 3 Measures. To measure relationship satisfaction, participants completed the satisfaction subscale of the Investment Model Scale (IMS; Rusbult et al., 1998), a 5-item measure rated on a 9-point scale $(1=$ completely disagree, $9=$ completely agree) that assesses how content individuals are in their current relationship (e.g., "Our relationship makes me very happy"). Participants also completed the commitment subscale of the IMS, a 7-item measure rated on a 9-point scale $(1=$ completely disagree, $9=$ completely agree) that assesses how dedicated individuals are to their current relationship (e.g., "I want our relationship to last for a very long time"). Scores were calculated by averaging responses across the subscale items, with higher scores indicating greater satisfaction and commitment, respectively.

Phase 2 Measures. Participants completed a one-item measure of global commitment (i.e., "How committed are you to your relationship today?") taken from the Perceived Relationship Quality Components Inventory (Fletcher et al., 2000). This item was rated on a 7 -point scale ( $1=$ not at all, $7=$ extremely $)$, with higher scores indicating greater daily commitment.

\section{Results}

\section{Frequency of Asymmetry}

Consistent with Study 1, asymmetry and asynchrony in commitment were common in this sample (see Table 1). At Phase 1,36.0\% of couples were categorized as asymmetrical.

\section{Association of Asymmetry and Asynchrony with Satisfaction}

To test whether commitment asymmetry was associated with later relationship satisfaction, we conducted comparable models to Study 1, with couples' categorical or 
continuous asymmetry at Phase 1 predicting each partner's satisfaction at Phase 3 (see Table 4). Inconsistent with Study 1, both categorical and continuous asymmetry were negatively associated with women's satisfaction 2.5 months later in the base model (Models 1a and 2a). When accounting for each partner's commitment score (Models $1 \mathrm{~b}$ and $2 \mathrm{~b}$ ), this effect was significant only for categorical asymmetry. Thus, women's satisfaction was significantly lower at Phase 3 if their relationship was categorized as asymmetrical at Phase 1. Consistent with Study 1, no asymmetry effects were significant for men. Partially consistent with Study 1, actors' commitment was associated with men and women having higher satisfaction 2.5 months later in the categorical and continuous asymmetry models.

To test whether commitment asynchrony was associated with later relationship satisfaction, we again compared partners' proportion of downturns, slopes, and intercepts. We recorded a downturn in commitment when participants reported lower commitment on a given day in Phase 2 relative to their commitment the previous day. We then divided the frequency of a participant's downturns by the total number of surveys they could have had a downturn recorded (i.e., number of times they completed two surveys in a row) to give a proportion of days with downturns, and calculated differences between partners' proportions. Partially consistent with Study 1, we found that differences in partners' proportion of downturns over Phase 2 did not predict either partner's satisfaction at Phase 3 in the base model (Model 3a; inconsistent with Study 1) or when controlling for each partner's proportion of downturns (Model 3b; consistent with Study 1). Consistent with Study 1, actors' proportion of downturns predicted men's and women's lower Phase 3 satisfaction. 
To examine differences in partners' trajectories of commitment over Phase 2 (14 days), we again performed an unconditional two-intercept growth model (separated by gender), with Time ( 0 = Phase 2 Day 1$)$ entered as a Level 1 predictor and daily commitment as the outcome. We then extracted the transformed residual scores from the unconditional growth model, and calculated differences between partners' slopes and intercepts. Although there were no significant effects for differences in partners' slopes in Study 1 , these differences significantly predicted women's later satisfaction in Study 2 in the base model (Model 4a) and controlling for each partner's slope (Model 4b), but not when controlling for differences in baseline commitment (intercepts) and each partner's baseline commitment (Model 4c). Inconsistent with Study 1, actors' slope did not predict satisfaction for men or women in any of the models.

Overall, we replicated the significance level of 30 out of 44 effects from Study 1 in Study 2 when predicting relationship satisfaction. There were six significant effects in Study 1 that were not in Study 2, and eight significant effects in Study 2 that were not in Study 1. 
Table 4. Study 2 effects of asymmetry and asynchrony predicting relationship satisfaction.

\begin{tabular}{|c|c|c|c|c|c|c|c|c|c|}
\hline \multirow[t]{2}{*}{ Model } & \multirow[t]{2}{*}{ Variable } & \multicolumn{4}{|c|}{ Man } & \multicolumn{4}{|c|}{ Woman } \\
\hline & & $b$ & $S E$ & $\bar{p}$ & $R^{2}$ & $b$ & $S E$ & $p$ & $R^{2}$ \\
\hline Model 1a & Categorical Asymmetry & .10 & .25 & .688 & .001 & .69 & .23 & .003 & .069 \\
\hline \multirow[t]{3}{*}{ Model 1b } & Categorical Asymmetry & -.20 & .25 & .430 & .005 & .49 & .23 & .038 & .036 \\
\hline & Actor commitment & .47 & .14 & .001 & .078 & .28 & .13 & .033 & .034 \\
\hline & Partner commitment & -.002 & .12 & .989 & $<.001$ & .11 & .11 & .334 & .007 \\
\hline Model 2a & Difference in Global Commitment & -.06 & .18 & .747 & .001 & -.36 & .17 & .036 & .032 \\
\hline \multirow[t]{3}{*}{ Model 2b } & Difference in Global Commitment & .09 & .17 & .584 & .002 & -.24 & .18 & .162 & .015 \\
\hline & Actor commitment & .45 & .14 & .001 & .075 & .31 & .13 & .018 & .041 \\
\hline & Partner commitment & -.01 & .11 & .917 & $<.001$ & .12 & .12 & .326 & .007 \\
\hline Model 3a & Asynchrony in downturns & -1.24 & .96 & .196 & .012 & -1.04 & .92 & .262 & .010 \\
\hline \multirow[t]{3}{*}{ Model 3b } & Asynchrony in downturns & -.68 & 1.04 & .514 & .003 & .56 & 1.01 & .581 & .002 \\
\hline & Actor's proportion of downturns & -2.80 & .93 & .003 & .059 & -2.64 & .85 & .002 & .074 \\
\hline & $\begin{array}{l}\text { Partner's proportion of } \\
\text { downturns }\end{array}$ & .97 & .86 & .260 & .010 & -1.07 & .80 & .182 & .012 \\
\hline Model 4a & Asynchrony in slopes & -2.63 & 3.04 & .388 & .006 & -8.49 & 2.90 & .004 & .067 \\
\hline \multirow[t]{3}{*}{ Model 4b } & Asynchrony in slopes & -2.86 & 3.13 & .362 & .007 & -7.30 & 2.98 & .016 & .050 \\
\hline & Actor's slope & 3.46 & 3.38 & .307 & .008 & 5.34 & 2.86 & .064 & .024 \\
\hline & Partner's slope & -.67 & 3.04 & .827 & $<.001$ & .35 & 3.08 & .910 & $<.001$ \\
\hline \multirow[t]{6}{*}{ Model 4c } & Asynchrony in slopes & 2.35 & 4.14 & .571 & .002 & -5.38 & 3.62 & .139 & .017 \\
\hline & Actor's slope & 4.90 & 3.95 & .217 & .012 & 2.69 & 3.56 & .452 & .004 \\
\hline & Partner's slope & -.49 & 3.62 & .892 & $<.001$ & 1.01 & 3.38 & .766 & .001 \\
\hline & Difference in intercepts & -.16 & .31 & .611 & .002 & .35 & .28 & .214 & .011 \\
\hline & Actor's intercept & .18 & .28 & .518 & .003 & .24 & .23 & .289 & .008 \\
\hline & Partner's intercept & .28 & .25 & .269 & .008 & .37 & .24 & .120 & .017 \\
\hline
\end{tabular}

Note. Each model included an intercept for men, an intercept for women, and actor's Phase 1 satisfaction (grand mean centered). Estimates of these additional effects can be found in our online supplemental material at https://osf.io/6xqg5/. Effects of interest (differences between partners) are bolded. Approximate effect sizes were computed using the formula $R^{2}=\frac{\left(d f_{\text {Numerator }} / d f_{\text {Denominator }}\right) * F}{1+\left(\left(\text { df }_{\text {Numerator }} / d f_{\text {Denominator }}\right) * F\right)}$ (Edwards et al., 2008). 


\section{Study 3}

Across Studies 1-2, only categorical asymmetry in Study 2 significantly predicted satisfaction when controlling for individuals' own and their partner's commitment or their commitment trajectories; all other effects were not significant. Thus, our first two studies provide growing evidence that couple-level asymmetry and asynchrony may not explain meaningful variation in relationship satisfaction over and above individual levels of commitment. However, given that there were some inconsistencies between the results of Studies 1 and 2 and some sample limitations of these previous studies (Study 1 data were $\sim 25$ years old, Study 2 occurred over a shorter time period where there may be relatively few fluctuations in global commitment), we sought to test our results in an additional study. Study 3 captured differences in partners' trajectories of commitment, with surveys completed each year for 12 years. In general, we anticipated that Study 3 would replicate the consistent findings of Studies 1-2 and resolve inconsistencies between the two. We again describe the typical levels of asymmetry and asynchrony between partners' global commitment and hypothesized that asymmetry and asynchrony would not consistently predict partners' future satisfaction and breakup. Instead, we expected that individuals' scores would better predict satisfaction and breakup.

\section{Methods}

\section{Participants}

We used data from the first 12 waves of the German Family Panel Study (pairfam), release 12.0 (Brüderl et al., 2020). ${ }^{5}$ Pairfam is a nationwide, randomly-selected sample of

\footnotetext{
${ }^{5}$ Data from the first seven waves of the pairfam were used in Finn et al.'s (2020) examination of the codevelopment of romantic partners (including the codevelopment of commitment), comparing across relationships that stayed together versus dissolved. Although our sample and measures include those from this prior work, their study was restricted to those who were in a relationship at Wave 1 and were in the 2
} 
private households in Germany, with the first 12 waves collected from 2008-2020. The panel conducts annual interviews with individuals, couples, and families (see Huinink et al., 2011 or the pairfam website [https://www.pairfam.de/en/] for more details).

Approximately 12,402 anchors were recruited at Wave 1, and this total was fairly evenly split between three age cohorts: 15-17, 25-27, and 35-37 years old. At Wave 11 a refreshment sample of approximately 5,000 anchors were added. We restricted our sample to couples with at least two consecutive waves of relevant data to test our hypotheses. The sample for the models with slopes and intercepts as predictors is further limited, as the growth-curve analyses involved in this process require at least 3 time points of data. Additionally, it is possible that anchors were involved in relationships with different partners over this 12-year period. We thus restricted our sample to the first couple partnership where both partners completed measures. That is, if an anchor reported being in a relationship with Partner A at Waves 1 and 2, but Partner B at Wave 3, even if both Partners A and B completed measures, we only used data from the anchor and Partner A. To avoid conflating breakup with being widowed (because in both cases the relationship ended), we also excluded cases where the partner died over the course of the 12-year study. Finally, we used the data only from different-sex couples, as our two-intercept models require differentiation between partners based on sex.

There were 6,639 couples who met these criteria, and they completed an average of 4.71 Waves $(S D=3.79)$ per person for a total of 62,584 unique data points. Of those who

older age cohorts, whereas our study included all first partnerships and all age groups. Additionally, we include data from all 12 waves rather than restricting to only the first seven. Thus, in combination with our additional datasets, any methodological similarities between the current and prior work do not constitute an overlapping publication. 
were in a relationship at Wave 1 , most were cohabitating with their current partner (78.3\%) and were married (56.6\%). The average monthly net household income was $€ 2702.48(S D=1383.40)$.

\section{Procedure}

Anchor participants were guided through a 1-hour computer-assisted interview at Wave 1 . Anchors received $€ 10$ in compensation for each interview completed. Due to the COVID-19 pandemic, at Wave 12 some interviews were conducted via telephone, rather than in person.

If an anchor was in a relationship at the time of an interview, they were asked if their partner could be contacted for an interview as well. If consent was given, a paper and pencil questionnaire was given to the anchor to relay to the partner or provided directly to the partner by the interviewer. A return envelope was provided, but partners could also have their responses collected by an interviewer. Partners received a $€ 5$ ticket for a charity lottery as compensation.

\section{Measures}

Global Commitment. A measure of global commitment was provided to all participants who reported being in a relationship, and was included at Waves 1-3, 5, 7, 9, and 11 . Scores were the average of participants' responses to a two-item measure based on Grau et al. (2001; e.g., "I would like for our partnership to last for a long time”). Possible responses were on a 5 -point scale $(1=$ not at all, $5=$ absolutely $)$.

Relationship Satisfaction. Relationship satisfaction was assessed in each wave for all respondents who reported being in a relationship, with one item from the German version of the Relationship Assessment Scale (Sander \& Böcker, 1993; "All in all, how 
satisfied are you with your relationship?"). Possible responses were on an 11-point scale (0 $=$ very dissatisfied, $10=$ very satisfied .

Breakup. At Wave 1, anchors completed questions regarding their relationship history. At each subsequent wave, they completed an updated relationship event history calendar. If an anchor ever reported they were in a relationship with a particular partner at one wave but were not in a relationship with that partner at the subsequent wave, breakup was coded ( 1 = broke up, $0=$ still together $)$.

\section{Results}

\section{Frequency of Asymmetry}

The relatively longer timeframe between waves in Study 3 necessitated a slightly different approach to analyses. For asymmetry, rather than using initial scores to predict final scores as in Studies 1-2 (i.e., commitment asymmetry at Phase 1 predicting outcomes at Phase 3) in Study 3 we calculated asymmetry at each wave where commitment was measured and used it to predict outcomes at the next wave. For example, because commitment was measured at Wave 1, differences between partners' scores at this time were calculated and then categorized as symmetrical or asymmetrical. These categorical and continuous asymmetry scores were then used as predictors of satisfaction and breakup by the following year at Wave 2 . Thus, it is possible that a couple that could be categorized as asymmetrical at Waves 1 and 2, then categorized as symmetrical at Wave 3 , and categorized as asymmetrical again by Wave 5 . Commitment asymmetry and asynchrony were less common in this sample (see Table 1), with $18.4 \%$ of all differences in commitment scores categorized as asymmetrical across couples and waves.

\section{Association of Asymmetry and Asynchrony with Satisfaction}


As mentioned above, in Study 3 categorical and continuous asymmetry at one wave were used to predict relationship satisfaction at the next wave. This required a small adjustment to the previous modeling approach, with satisfaction models in Study 3 run as two-level crossed models with individuals nested within couples crossed with time to account for the fact that partners answered surveys at the same wave. Other than this change, the analytic approach we used was consistent with that of the prior studies, including using a model building approach and controlling for prior satisfaction in all models. As seen in Table 5, although categorical and continuous asymmetry predicted males' and females' relationship satisfaction at the next wave in the base models (Models 1a and 2a; partially consistent with Study 2), effects were nonsignificant when accounting for each partner's commitment scores (Models $1 \mathrm{~b}$ and $2 \mathrm{~b}$ ). Instead, actor and partner commitment scores significantly predicted males' and females' relationship satisfaction one year later. These effects are largely consistent with Studies 1-2.

For commitment asynchrony over time, we first calculated the proportion of downturns in partners' commitment. Commitment was not measured at consistent intervals across this study (every year for the first 3 years, then every other year after that). Thus, for consistency it was necessary to calculate the frequency of downturns by comparing data from each wave to its corresponding score two waves earlier (essentially dropping the scores from Wave 2 while still providing the highest possible number of consistently-spaced data points). We determined the total number of times that commitment decreased from two years prior and divided this by the total number of possible downturn waves (i.e., they completed the commitment measure in two consecutive odd waves) to get the proportion of downturns. Because Study 3 did not have a 
separate follow-up phase as in Studies 1 and 2, we used satisfaction at the last available time point for our outcome. That is, we used differences in partners' proportion of downturns from Waves 1-12 to predict their relationship satisfaction at Wave 12. Consistent with Study 1 but inconsistent with Study 2, the difference between partners' proportion of downturns was a significant predictor of males' and females' Wave 12 relationship satisfaction in the base model (Model 3a), but not when controlling for each partners' proportion of downturns. Instead, consistent with Studies 1 and 2, actors' proportion of downturns significantly predicted males' and females' satisfaction. Inconsistent with both prior studies, partners' proportion of downturns also predicted males' and females' satisfaction in Study 3.

To examine the effects of differences in partners' trajectories of commitment over time, we again ran a two-intercept growth model and extracted the slopes and intercepts for each partner, entering these values and the difference between partners on these values to predict Wave 12 satisfaction. Differences between partners' slopes negatively predicted relationship satisfaction in the base model and when controlling for each partner's slope (Models 4a and 4b), which was previously significant only for women in Study 2. Consistent with Studies 1-2, when controlling for differences in intercepts and each partner's intercept (Model 4c), differences in slopes no longer predicted males' or females' satisfaction. Inconsistent with both prior studies, actors' slope was a significant predictor of males' Wave 12 relationship satisfaction in Models 4b and 4c.

Overall, 19 out of 44 effects were consistent across all three studies, with 16 of these being null effects. Males' commitment was associated with their own later relationship satisfaction in 5/6 models across studies, and this effect was also significant in 4/6 models 
across studies for females. Males' and females' proportion of downturns was also associated with their own later relationship satisfaction across all studies. 
Table 5. Study 3 effects of asymmetry and asynchrony predicting relationship satisfaction.

\begin{tabular}{|c|c|c|c|c|c|c|c|c|c|}
\hline \multirow[t]{2}{*}{ Model } & \multirow[t]{2}{*}{ Variable } & \multicolumn{4}{|c|}{ Man } & \multicolumn{4}{|c|}{ Woman } \\
\hline & & $b$ & $S E$ & $p$ & $R^{2}(95 \% \mathrm{CI})$ & $b$ & $S E$ & $p$ & $R^{2}(95 \% \mathrm{CI})$ \\
\hline Model 1a & Categorical Asymmetry & .57 & .04 & $<.001$ & .014 & .53 & .04 & $<.001$ & .011 \\
\hline \multirow[t]{3}{*}{ Model 1b } & Categorical Asymmetry & .04 & .05 & .424 & $<.001$ & .04 & .06 & .461 & $<.001$ \\
\hline & Actor commitment & .55 & .04 & $<.001$ & .017 & .57 & .04 & $<.001$ & .019 \\
\hline & Partner commitment & .25 & .03 & $<.001$ & .005 & .19 & .04 & $<.001$ & .002 \\
\hline Model 2a & Difference in Global Commitment & -.43 & .03 & $<.001$ & .017 & -.43 & .03 & $<.001$ & .017 \\
\hline \multirow[t]{3}{*}{ Model 2b } & Difference in Global Commitment & -.01 & .04 & .783 & $<.001$ & -.06 & .04 & .136 & $<.001$ \\
\hline & Actor commitment & .56 & .04 & $<.001$ & .016 & .55 & .04 & $<.001$ & .015 \\
\hline & Partner commitment & .25 & .04 & $<.001$ & .004 & .17 & .04 & $<.001$ & .002 \\
\hline Model 3a & Asynchrony in downturns & -.91 & .22 & $<.001$ & .015 & -.51 & .22 & .019 & .004 \\
\hline \multirow[t]{3}{*}{ Model 3b } & Asynchrony in downturns & .01 & .26 & .962 & $<.001$ & .22 & .26 & .397 & .001 \\
\hline & Actor's proportion of downturns & -1.60 & .26 & $<.001$ & .031 & -1.14 & .25 & $<.001$ & .017 \\
\hline & Partner's proportion of downturns & -.57 & .23 & .016 & .005 & -.61 & .24 & .010 & .005 \\
\hline Model 4a & Asynchrony in slopes & -.33 .16 & 6.45 & $<.001$ & .014 & -29.87 & 6.44 & $<.001$ & .010 \\
\hline \multirow[t]{3}{*}{ Model 4b } & Asynchrony in slopes & -18.40 & 6.62 & .006 & .004 & -16.93 & 6.66 & .011 & .003 \\
\hline & Actor's slope & 17.94 & 4.77 & $<.001$ & .008 & 6.51 & 5.18 & .209 & .001 \\
\hline & Partner's slope & -6.45 & 5.05 & .202 & .001 & 4.67 & 4.75 & .325 & $<.001$ \\
\hline \multirow[t]{6}{*}{ Model 4c } & Asynchrony in slopes & -7.43 & 7.77 & .339 & $<.001$ & -1.39 & 7.77 & .858 & $<.001$ \\
\hline & Actor's slope & 14.13 & 4.86 & .004 & .005 & 9.96 & 5.47 & .069 & .002 \\
\hline & Partner's slope & -.06 & 5.34 & .991 & $<.001$ & 2.53 & 4.85 & .602 & $<.001$ \\
\hline & Difference in intercepts & .03 & .32 & .918 & $<.001$ & -.28 & .30 & .344 & $<.001$ \\
\hline & Actor's intercept & .79 & .23 & .001 & .006 & 1.05 & .22 & $<.001$ & .011 \\
\hline & Partner's intercept & .04 & .22 & .854 & $<.001$ & .07 & .22 & .742 & $<.001$ \\
\hline
\end{tabular}

Note. Each model included an intercept for men, an intercept for women, and actor's satisfaction the previous wave (grand mean centered). Estimates of these additional effects can be found in our online supplemental material at https://osf.io/v8syf/. Effects of interest (differences between partners) are bolded.

Approximate effect sizes were computed using the formula $R^{2}=\frac{\left(d f_{\text {Numerator }} / d f_{\text {Denominator }}\right) * F}{1+\left(\left(\text { df }_{\text {Numerator }} / d f_{\text {Denominator }}\right) * F\right)}$ (Edwards et al., 2008). 


\section{Association of Asymmetry and Asynchrony with Breakup}

In Study 3, we examined effects for categorical and continuous asymmetry similarly to those for satisfaction, as asymmetry at one wave was used to predict whether the couple had broken up by the next wave (see Table 6). Thus, we ran these models as two-level crossed models with individuals nested within couples crossed with time. However, consistent with Study 1 we followed the specifications of Loeys et al. (2014) for conducting APIMs for categorical dyadic data given that breakup is a binary outcome. Consistent with Study 1, categorical and continuous asymmetry were significant predictors of breakup in the base models (Models 1a and 2a) but were nonsignificant when controlling for each partner's commitment score (Models $1 \mathrm{~b}$ and $2 \mathrm{~b}$ ). Instead, males' and females' commitment were negatively associated with breakup one year later. This is partially consistent with Study 1, where these effects were significant only for females.

For asynchrony, we used differences in partners' proportion of downturns and slopes to predict whether they ever broke up across all 12 waves. We again ran APIMs for categorical dyadic data using GEEs, but in this case the models were simply two-level models (individuals nested within couples). Partially consistent with Study 1, differences between partners' proportion of downturns positively predicted whether they broke up in both the base model (Model 3a, consistent with Study 1) and when controlling for each partner's proportion of downturns (Model 3b, inconsistent with Study 1). Although significant only for females in Study 1, in Study 3 both males' and females' proportion of downturns significantly predicted breakup. Finally, the effect for differences in partner's slopes was significant in the base model (Model 4a), when controlling for each partner's slope (Model 4b), and when controlling for each partner's slope, baseline commitment 
(intercept), and the difference between partners' baseline commitment (Model 4c), but effects were in the opposite direction than one might expect. That is, differences between partners' slopes were negatively associated with breakup in all cases. Inconsistent with Study 1, males' slopes and baseline commitment were negatively associated with breakup. Females' slopes were positively associated with breakup in Model 4b, which is in the opposite direction of Study 1; however, this effect was null when controlling for differences in partners' intercepts and each partner's intercept (Model 4c). Consistent with Study 1, females' baseline commitment was negatively associated with breakup.

Overall, 10 out of 22 effects for breakup were consistent across Studies 1 and 3, with two of these being null effects. Females' commitment, proportion of downturns, and baseline commitment (intercept) were consistently associated with breakup across studies. Categorical asymmetry, continuous asymmetry, asynchrony as differences in proportion of downturns, and asynchrony as differences in slopes were consistently associated with breakup in the base models. However, asymmetry consistently failed to predict breakup when controlling for each partner's commitment and asynchrony was inconsistently associated with breakup when controlling for actors' scores. 
Table 6. Study 3 effects of asymmetry and asynchrony predicting breakup.

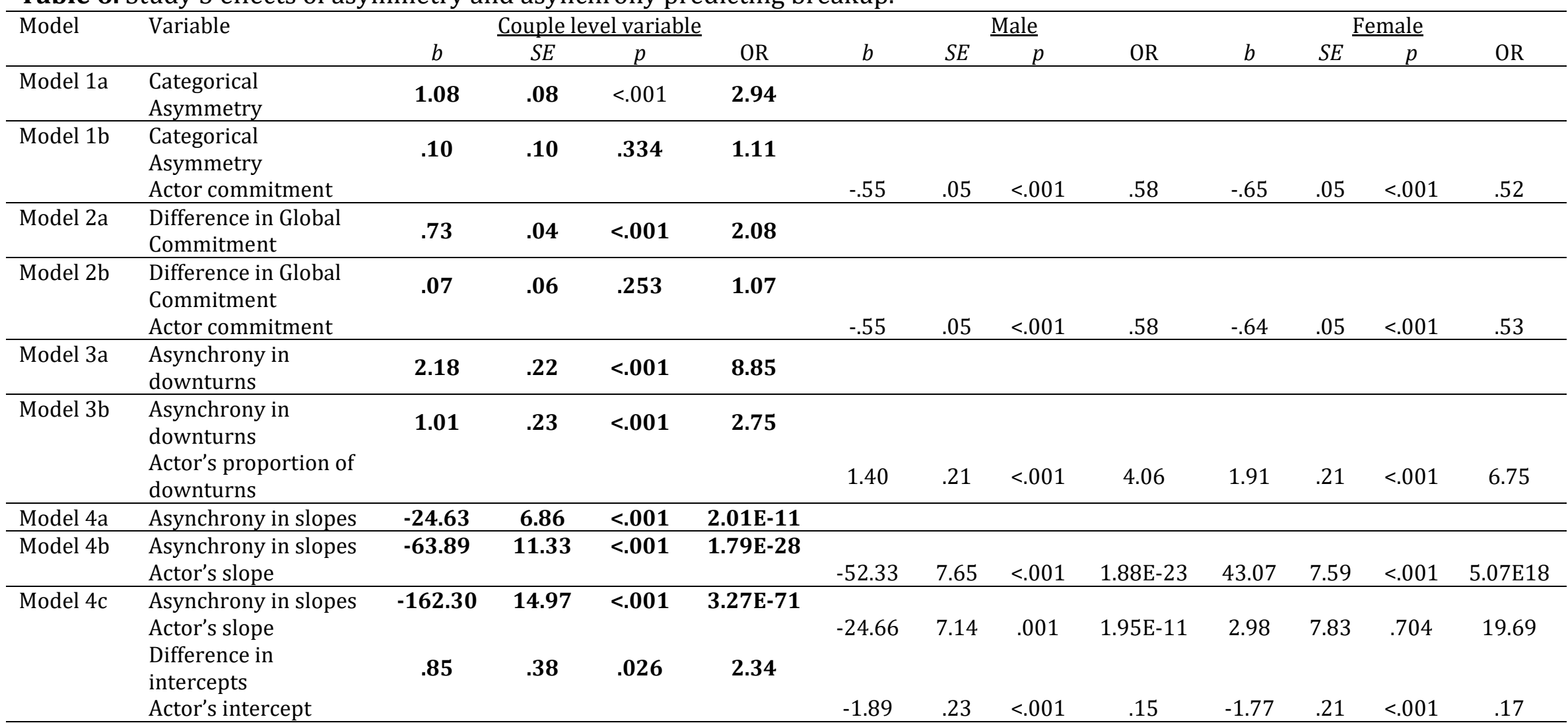

Note. Since we are predicting a couple-level outcome and all couples are different-sex, the actor effect for males is equal to the partner effect for females, and vice versa. Thus, we only present the actor effects. Effects of interest (differences between partners) are bolded. OR is odds ratio, which is an exponentiated $b$. 


\section{General Discussion}

Across three longitudinal, dyadic studies we examined the associations of partners' commitment asymmetry (cross-sectional differences between partners) and asynchrony (differences in the trajectory of commitment over time) with their later relationship satisfaction and breakup. Overall, no type of commitment asymmetry or asynchrony consistently predicted satisfaction or breakup when controlling for each partner's commitment or commitment trajectory. These null findings have important implications for future research, as they demonstrate that the emphasis placed on a discrepancy-based measurement approaches used in prior research may not be an effective means of examining the factors that contribute to relationship success. Instead, actors' commitment and proportion of downturns were most consistently associated with later satisfaction experiences, and women's commitment, proportion of downturns, and baseline commitment were consistently associated with later breakup.

We propose three potential reasons for our null results of commitment asymmetry and asynchrony. The first and perhaps most likely reason is that any differences between partners have little impact on relationships when considered in the context of commitment more generally. The differences found between partners' commitment in the current research were small ( $\sim 1$ scale point), which is consistent with prior research demonstrating that partners tend to be very similar in their commitment (Weigel, 2010). Thus, partners in intact relationships may simply be more similar than they are different when it comes to their long-term orientation toward their relationship, resulting in little to no effect of differences between partners on relational outcomes. Another explanation could be that actual differences between partners may not always be an ideal means of 
examining the impact of discrepancies. Instead, perhaps researchers should focus on the differences that partners perceive to exist between them. Indeed, perceived differences in commitment predict relationship satisfaction and stability (Sprecher et al., 2006; Tan et al., 2020). Additionally, relationship research more broadly has demonstrated that actors' relationship-specific experiences influence relationship quality to a greater extent than individual differences or partner's experiences (Joel et al., 2020), and that perceptions may be more strongly associated with relational well-being than actual behavior (Dobson et al., 2021). On the other hand, romantic partners are fairly accurate in their perceptions of their partner's commitment, and actual (but not perceived) similarity in commitment is associated with relationship satisfaction (see Weigel, 2010). Thus, there is mixed evidence for this potential explanation, and future work exploring the comparative impact of perceived and actual differences in commitment may prove fruitful. Finally, it is possible that asymmetry and asynchrony between partners impact relationships, but have only immediate (i.e., cross-sectional) effects and thus were not illuminated in the current longitudinal research. Although we view this as a plausible explanation for the discrepancy between the current null results and the significant findings of prior work, if true, it begs the question of how meaningful these effects are for the long-term success of relationships if the effects of discrepancies between partners do not accumulate or persist over time.

Interestingly, the most consistent predictor of men's and women's satisfaction for across studies was their own experiences of downturns in commitment (i.e., lower commitment than previously reported). Women's proportion of downturns was also consistently associated with breakup. These findings are consistent with prior research demonstrating the deleterious effects of commitment fluctuations (Knopp et al., 2014) and 
the profound impact of negative experiences (for reviews, see Baumeister et al., 2001; Rozin \& Royzman, 2001). The effects for breakup are also consistent with prior research on heterosexual relationships demonstrating that women's commitment in particular is associated with breakup, with 54\% of relationships breaking up over the next two years when the female partner has lower commitment than the male partner (Stanley et al., 2017). Thus, partners' experiences of downturns in commitment, and women's experiences in particular, are an important predictor of future relationship quality and stability that deserve greater attention in future research.

Perhaps unsurprisingly, actor's commitment was the second most consistent predictor of relationship satisfaction and breakup, predicting males' satisfaction in Study 1, men's and women's satisfaction in Study 2, and males' and females' satisfaction and breakup in Study 3. This is consistent with myriad prior studies demonstrating sizeable correlations between commitment and relationship satisfaction (e.g., Rusbult, 1983). Additionally, a meta-analysis of various predictors of relationship dissolution found that lower commitment is the second strongest predictor of breakup (Le et al., 2010), further demonstrating commitment's importance in relationships.

Given that effects of asymmetry and asynchrony were largely null, even across four different ways of measuring these effects, our findings suggest that differences in commitment between partners may not be indicative of future relationship success. However, if future research continues examining such differences, our findings suggest that they may be more likely to find meaningful effects over time if examining asynchrony versus asymmetry. When controlling for actor and partner effects, there were consistently null results for both categorical and continuous asymmetry, with one exception 
(categorical asymmetry in Study 2 for women's satisfaction). For asynchrony, however, although results for satisfaction were also largely null when controlling for actor and partner effects, there were some inconsistent effects for breakup regarding couples' differences in their proportion of downturns and slopes. It is possible that because Study 1 was conducted over a comparatively short 9-month timeframe (whereas Study 3 spanned 12 years), there may have been couples who were together at the end of Study 1 but eventually broke up, and these experiences were not captured in the data. Given the longer timeframe covered by Study 3, the significant effects associated with breakup for this study may be more representative of true breakup experiences. Thus, our results suggest examining differences in couples' trajectories of commitment over time (vs. at a single time point) is the more promising avenue for future research in this area.

There were limitations to the current research that may have influenced the consistency of the effects. First, data for each study were part of larger studies, and thus we did not have control over the measures used. This resulted in slightly different measures of commitment across studies, with the most marked difference being that asynchrony was measured using commitment to wed rather than global commitment in Study 1. Additionally, each study was conducted over a different timeframe, both in the dates the data were collected and the timespan over which the study was conducted. Finally, the data for each study were collected in a different country. Although these factors may have influenced the consistency of some of the effects across studies, they also greatly strengthen our confidence in the results that were consistent. That is, we found consistently null results for the impact of differences in partner's commitment on future relationship satisfaction across measures of commitment, date and timespan of the study, 
and across three different countries. Additionally, differences across studies allowed for the limitations of a single study to be addressed in the others. For example, it could be argued that the short time span of Study 2 (particularly the 14-day diary portion used for the asynchrony analyses) may not have allowed for significant change in commitment to occur. This limitation was addressed in Studies 1 and 3, where commitment was measured over months and years, offering ample opportunity for fluctuations to occur. Similarly, it could be argued that the data for Study 1 may be less relevant to current relationship experiences, as they were collected about 25 years ago. But the final phases of data collection for Studies 2 and 3 occurred over the past two years.

An additional limitation of this work stems from the nature of how the data must be collected to examine differences between partners: couples who choose to participate in research together are less likely to break up than couples where only one partner participates (Park et al., 2021). Thus, the samples of couples recruited in the current research may have been more committed and satisfied in their relationships compared to the general public and may not be fully representative of diverse relationship experiences. This limitation is partially addressed in Study 3, as this study did not actively recruit couples but instead recruited anchors and later requested that their partners participate. Additionally, Study 1 used a measure of commitment to wed for the asynchrony analyses, which focuses on a particular facet of global commitment (i.e., partners' future orientation: the belief that the relationship will continue into the future). It is possible that although partners' intention to persist in their relationships (another component of commitment; their motivation to stay in the relationship) may be particularly high in couples who choose to participate in longitudinal research together, by instead focusing on partners' future 
orientation in Study 1 we may have received more variable responses in commitment to wed that are more representative of the general population. Finally, the generalizability of our results is further limited by our samples. We analyzed data from different-sex/gender couples only, and the vast majority of participants across samples were White. Thus, an exciting opportunity for future research lies in establishing the generalizability of our findings in more diverse samples.

In conclusion, we found little evidence that either asymmetry or asynchrony in romantic partners' commitment are effective indicators of partners' future satisfaction and breakup. Instead, actors' proportion of downturns in commitment and global commitment scores more consistently predicted these relationship outcomes. Our findings contribute to ongoing debates in the literature regarding the validity of different measures and construct operationalizations in psychology in general and relationship science in particular, and lend insight into the most fruitful avenues for future work wishing to compare partners' relationship experiences. Although there may be many ways to test how partners' commitment predicts satisfaction and breakup over time, there appears to be nothing as robust as their own experiences of relationship decline and their individual desire for the relationship to last. 


\section{References}

Antonucci, T. C., Lansford, J. E., \& Akiyama, H. (2001). Impact of Positive and Negative Aspects of Marital Relationships and Friendships on Well-Being of Older Adults. Applied Developmental Science, 5(2), 68-75. https://doi.org/10.1207/S1532480XADS0502_2

Baumeister, R. F., Bratslavsky, E., Finkenauer, C., \& Vohs, K. D. (2001). Bad is Stronger than Good. Review of General Psychology, 5(4), 323-370. https://doi.org/10.1037/10892680.5.4.323

Brüderl, J., Drobnič, S., Hank, K., Neyer, Franz. J., Walper, S., Alt, P., Bozoyan, C., Finn, C., Frister, R., Garrett, M., Gonzalez Avilés, T., Greischel, H., Gröpler, N., Hajek, K., Herzig, M., Huyer-May, B., Lenke, R., Minkus, L., Peter, T., ... Wilhelm, B. (2020). The German Family Panel (pairfam)Beziehungs- und Familienpanel (pairfam) (11.0.0) [Data set]. GESIS Data Archive. https://doi.org/10.4232/PAIRFAM.5678.11.0.0

Dobson, K., Stanton, S. C. E., \& Veeravalli, A. (2021). The Power of Potential: Relational SelfExpansion Potential and Daily Self-Expansion Behaviors Uniquely Contribute to Relationship Quality Over Time [Preprint]. PsyArXiv. https://doi.org/10.31234/osf.io/h9wmj

Edwards, L. J., Muller, K. E., Wolfinger, R. D., Qaqish, B. F., \& Schabenberger, O. (2008). An R² statistic for fixed effects in the linear mixed model. Statistics in Medicine, 27, 61376157.

Finn, C., Johnson, M. D., \& Neyer, F. J. (2020). Happily (n)ever after? Codevelopment of romantic partners in continuing and dissolving unions. Developmental Psychology, 56(5), 1022-1028. https://doi.org/10.1037/dev0000897 
Fletcher, G. J. O., Simpson, J. A., \& Thomas, G. (2000). The Measurement of Perceived Relationship Quality Components: A Confirmatory Factor Analytic Approach. Personality and Social Psychology Bulletin, 26(3), 340-354. https://doi.org/10.1177/0146167200265007

Grau, I., Mikula, G., \& Engel, S. (2001). Skalen zum Investitionsmodell von Rusbult [Measuring components of the Investment Model by Rusbult]. Zeitschrift Für Sozialpsychologie, 32(1), 29-44. https://doi.org/10.1024/0044-3514.32.1.29

Hadden, B. W., Smith, C. V., \& Knee, C. R. (2014). The way I make you feel: How relatedness and compassionate goals promote partner's relationship satisfaction. The Journal of Positive Psychology, 9(2), 155-162. https://doi.org/10.1080/17439760.2013.858272

Holt-Lunstad, J., Birmingham, W., \& Jones, B. Q. (2008). Is There Something Unique about Marriage? The Relative Impact of Marital Status, Relationship Quality, and Network Social Support on Ambulatory Blood Pressure and Mental Health. Annals of Behavioral Medicine, 35(2), 239-244. https://doi.org/10.1007/s12160-008-9018-y

Huinink, J., Brüderl, J., Nauck, B., Walper, S., Castiglioni, L., \& Feldhaus, M. (2011). Panel analysis of intimate relationships and family dynamics (pairfam): Conceptual framework and design. Zeitschrift Für Familienforschung, 23(1), 77-101.

Huston, T. L., \& Vangelisti, A. L. (1991). Socioemotional behavior and satisfaction in marital relationships: A longitudinal study. Journal of Personality and Social Psychology, 61(5), 721-733. https://doi.org/10.1037/0022-3514.61.5.721

Joel, S., Eastwick, P. W., Allison, C. J., Arriaga, X. B., Baker, Z. G., Bar-Kalifa, E., Bergeron, S., Birnbaum, G. E., Brock, R. L., Brumbaugh, C. C., Carmichael, C. L., Chen, S., Clarke, J., 
Cobb, R. J., Coolsen, M. K., Davis, J., de Jong, D. C., Debrot, A., DeHaas, E. C., ... Wolf, S. (2020). Machine learning uncovers the most robust self-report predictors of relationship quality across 43 longitudinal couples studies. Proceedings of the National Academy of Sciences, 117(32), 19061-19071.

https://doi.org/10.1073/pnas.1917036117

Kenny, D. A., Kashy, D. A., \& Cook, W. L. (2006). Dyadic data analysis. Guilford Press.

Knopp, K., Rhoades, G. K., Stanley, S., Owen, J., \& Markman, H. (2014). Fluctuations in commitment over time and relationship outcomes. Couple and Family Psychology: Research and Practice, 3(4), 220-231. https://doi.org/10.1037/cfp0000029

Le, B., Dove, N. L., Agnew, C. R., Korn, M. S., \& Mutso, A. A. (2010). Predicting nonmarital romantic relationship dissolution: A meta-analytic synthesis. Personal Relationships, 17(3), 377-390. https://doi.org/10.1111/j.1475-6811.2010.01285.x

Loeys, T., Cook, W., De Smet, O., Wietzker, A., \& Buysse, A. (2014). The actor-partner interdependence model for categorical dyadic data: A user-friendly guide to GEE: Dyadic data analysis using GEE. Personal Relationships, 21(2), 225-241. https://doi.org/10.1111/pere.12028

Machia, L. V., \& Ogolsky, B. G. (2021). The Reasons People Think About Staying and Leaving Their Romantic Relationships: A Mixed-Method Analysis. Personality and Social Psychology Bulletin, 47(8), 1279-1293. https://doi.org/10.1177/0146167220966903

Mark, K. P., \& Murray, S. H. (2012). Gender Differences in Desire Discrepancy as a Predictor of Sexual and Relationship Satisfaction in a College Sample of Heterosexual 
Romantic Relationships. Journal of Sex \& Marital Therapy, 38(2), 198-215. https://doi.org/10.1080/0092623X.2011.606877

Niehuis, S., Reifman, A., Feng, D., \& Huston, T. L. (2016). Courtship Progression Rate and Declines in Expressed Affection Early in Marriage: A Test of the Disillusionment Model. Journal of Family Issues, 37(8), 1074-1100. https://doi.org/10.1177/0192513X14540159

Ogolsky, B. G., Surra, C. A., \& Monk, J. K. (2016). Pathways of Commitment to Wed: The Development and Dissolution of Romantic Relationships: Pathways of Commitment. Journal of Marriage and Family, 78(2), 293-310. https://doi.org/10.1111/jomf.12260

Park, Y., Impett, E. A., \& MacDonald, G. (2021). Generalizability of Results From Dyadic Data: Participation of One Versus Two Members of a Romantic Couple Is Associated With Breakup Likelihood. Personality and Social Psychology Bulletin, 47(2), 232-240. https://doi.org/10.1177/0146167220920167

Rozin, P., \& Royzman, E. B. (2001). Negativity Bias, Negativity Dominance, and Contagion. Personality and Social Psychology Review, 5(4), 296-320. https://doi.org/10.1207/S15327957PSPR0504_2

Rusbult, C. E. (1980). Commitment and satisfaction in romantic associations: A test of the investment model. Journal of Experimental Social Psychology, 16(2), 172-186. https://doi.org/10.1016/0022-1031(80)90007-4

Rusbult, C. E. (1983). A longitudinal test of the investment model: The development (and deterioration) of satisfaction and commitment in heterosexual involvements. 
Journal of Personality and Social Psychology, 45(1), 101-117.

https://doi.org/10.1037/0022-3514.45.1.101

Rusbult, C. E., Martz, J. M., \& Agnew, C. R. (1998). The Investment Model Scale: Measuring commitment level, satisfaction level, quality of alternatives, and investment size. Personal Relationships, 5(4), 357-387. https://doi.org/10.1111/j.14756811.1998.tb00177.x

Sander, J., \& Böcker, S. (1993). Die Deutsche Form der Relationship Assessment Scale (RAS): Eine kurze Skala zur Messung der Zufriedenheit in einer Partnerschaft [The German version of the Relationship Assessment Scale (RAS): A short scale for measuring satisfaction in a dyadic relationship]. Diagnostica, 39(1), 55-62.

Schimmack, U. (2020). A meta-psychological perspective on the decade of replication failures in social psychology. Canadian Psychology/Psychologie Canadienne, 61(4), 364-376. https://doi.org/10.1037/cap0000246

Sprecher, S., Schmeeckle, M., \& Felmlee, D. (2006). The Principle of Least Interest: Inequality in Emotional Involvement in Romantic Relationships. Journal of Family Issues, 27(9), 1255-1280. https://doi.org/10.1177/0192513X06289215

Stanley, S. M., Rhoades, G. K., Scott, S. B., Kelmer, G., Markman, H. J., \& Fincham, F. D. (2017). Asymmetrically committed relationships. Journal of Social and Personal Relationships, 34(8), 1241-1259. https://doi.org/10.1177/0265407516672013

Stanton, S. C. E., Spence, K., Kähkönen, J. E., \& Dobson, K. (2020). Individual and dyadic associations among relational self-expansion potential, affect, and perceived health. Personal Relationships, 27(3), 550-570. https://doi.org/10.1111/pere.12331 
Surra, C. A., \& Gray, C. E. (2000). A typology of processes of commitment to marriage: Why do partners commit to problematic relationships? In L. J. Waite, C. Backrach, M. Hindin, E. Thomson, \& A. Thornton (Eds.), The ties that bind: Perspectives on marriage and cohabitation (pp. 253-280). Aldine de Gruyter.

Tan, K., Agnew, C. R., \& Hadden, B. W. (2020). Seeking and Ensuring Interdependence: Desiring Commitment and the Strategic Initiation and Maintenance of Close Relationships. Personality and Social Psychology Bulletin, 46(1), 36-50. https://doi.org/10.1177/0146167219841633

van Walraven, C., \& Hart, R. G. (2008). Leave 'em Alone-Why Continuous Variables Should Be Analyzed as Such. Neuroepidemiology, 30(3), 138-139. https://doi.org/10.1159/000126908

Weigel, D. J. (2010). Mutuality of commitment in romantic relationships: Exploring a dyadic model. Personal Relationships, 17(4), 495-513. https://doi.org/10.1111/j.14756811.2010.01303.x

Weiser, D., Hilliard, T., \& Knox, D. (2018). “I thought you loved me too?”: Outcomes of discrepant involvement in romantic relationships. Interpersona: An International Journal on Personal Relationships, 12(2), 267-282. https://doi.org/10.5964/ijpr.v12i2.313 